\title{
Introduction to the artificial intelligence in pediatric radiology imaging special issue
}

\author{
Amaka C. Offiah $^{1}$ (D) Safwan Halabi ${ }^{2}$
}

Received: 26 July 2021 / Revised: 26 July 2021 / Accepted: 16 August 2021 / Published online: 8 September 2021

(C) The Author(s), under exclusive licence to Springer-Verlag GmbH Germany, part of Springer Nature 2021

What should be included in a list of things people either love or hate (or love to hate): skinny jeans, marmite, Facebook status updates, giving evidence in court, artificial intelligence (AI)? Alas, for the "haters," something else that these things all have in common? They're here to stay, yes, even (perhaps especially) AI. According to Sukant Ratnakar (author of Open the Windows), "The biggest fear of life is the fear of change" [1]. It is probable that the haters of AI fear a disruption to the working lives of radiologists, or even worse - a complete replacement of radiologists by machines.

In the opinion of Eliezer Yudkowsky (AI theorist and writer), "By far the greatest danger of artificial intelligence is that people conclude too early that they understand it" [2]. At the last Pediatric Radiology editors' meeting, held in Helsinki during the European Society of Paediatric Radiology (ESPR) 2019 conference, (I know, I know - so long ago, and the reality of COVID-19 and how it has changed our world is even now still being computed by us all), Dr. Øystein Olsen asked for ideas for future special issues of our journal. I suggested artificial intelligence, not because I'm an expert in the area, but precisely because I realized my understanding of AI in general, and particularly as it relates to pediatric radiology, was somewhat limited. Serendipitously, Dr. Safwan Halabi had floated the idea of a special issue on imaging informatics and artificial intelligence to Dr. Peter Strouse soon after Larson and colleagues [3] were awarded

Amaka C. Offiah

a.offiah@sheffield.ac.uk

1 Academic Unit of Child Health,

University of Sheffield,

Damer Street Building, Western Bank,

Sheffield S10 2TH, UK

2 Department of Medical Imaging,

Ann \& Robert H. Lurie Children's Hospital of Chicago,

Chicago, IL, USA the Caffey for Best Basic Science Research Paper, titled "Performance of a deep neural network learning model in assessing skeletal maturity on pediatric hand radiographs," at the Society for Pediatric Radiology's annual meeting in 2017.

Once the idea had been approved, then unlike some special issues of the journal that have been based on relevant meetings or conference sessions, this issue had to be developed de novo, as it were, and it made perfect sense for Dr. Halabi and myself to be co-editors. We were fortunate that many of the leading authorities and researchers in the realm of deep learning and artificial intelligence in medical imaging identify as pediatric radiologists and have contributed to the pediatric radiology "augmented intelligence" armamentarium. Not only do these domain experts represent a large swath of pediatric imaging subspecialties, but they also represent multiple continents and their respective, diverse patient populations and health care settings.

First, we decided on the outline of the issue and agreed to begin with a general section aimed at giving the reader a clearer understanding of what is meant by $\mathrm{AI}$ and how it does or might impact day-to-day radiology practice. In this section we have a contribution by Erich Sorantin exploring what is meant by "augmented radiology." Ramesh Iyer then gives an overview of AI; Kikky van Leewen discusses quality, safety and value-based health care; David Larson concentrates on adoption and implementation of diagnostic algorithms; while the last two papers in this section are related to research, with Anuj Pareek and Matt Lungren identifying requirements for performing AI-related research and Susan Shelmerdine identifying key points that reviewers should consider when assessing AI-related studies.

We wanted the second section of this issue to have depth as well as breadth and to address current as well as potential roles of AI. To achieve this, we have papers covering specific subspecialities within pediatric radiology, namely abdominal imaging (Jonathan Dillman), cardiovascular imaging (Andrew Taylor), interventional radiology (Sudhen Desai), central nervous system imaging (Stavros Stivaros), chest imaging 
(Steven Schalekamp), maternal and fetal imaging (Safwan Halabi) and musculoskeletal imaging (Amaka Offiah).

We are extremely grateful to all the authors, who contributed their papers in what (because of the pandemic) has been a difficult period. We hope that you, our readers, enjoy the papers and learn from them, as much as we have done. We also want to express our gratitude to Drs. Olsen and Strouse for continuously striving to keep our specialty and journal both timely and relevant to all the providers who benefit from pediatric imaging and, ultimately, all the patients and families we serve.

Rooting for the machines, Claude Shannon (engineer, 1916-2001) visualized "a time when we will be to robots what dogs are to humans" [4]. Neither Dr. Halabi nor I would go quite that far, but perhaps having read this issue, any "AI haters" will no longer be filled with dread but can anticipate a time when they and AI will become best friends.

\section{Declarations}

Conflicts of interest Amaka C. Offiah has conducted research with Visiana in relation to BoneXpert Software and has received funding from
Alexion for the development of dREAMS (Dynamic Radiological Electronic Atlas of Malformation Syndromes). Safwan Halabi is a paid adviser for Change Healthcare.

\section{References}

1. Ratnakar S (2011) Open the windows. Hay House India, New Delhi

2. Goodreads (2021) Eliezer Yudkowsky: quotable quote: "By far the greatest danger of artificial intelligence is that people conclude too early that they understand it." https://www.goodreads.com/quotes/ 1228197-by-far-the-greatest-danger-of-artificial-intelligence-is-that. Accessed 13 Aug 2021

3. Larson DB, Chen MC, Lungren MP et al (2018) Performance of a deep neural network learning model in assessing skeletal maturity on pediatric hand radiographs. Radiology 287:313-322

4. The Famous People (n.d.) 11 notable Claude Shannon quotes for the techno geek. https://quotes.thefamouspeople.com/claude-shannon8078.php. Accessed 13 Aug 2021

Publisher's note Springer Nature remains neutral with regard to jurisdictional claims in published maps and institutional affiliations. 